\title{
Maternal depressive symptoms and stress during pregnancy as predictors of gestational age at birth and standardized body mass index from birth up to 2 years of age
}

\author{
Janina Eichler ${ }^{1 *}$, Ricarda Schmidt ${ }^{1}$, Tanja Poulain ${ }^{2,3}$, Andreas Hiemisch $^{2,3}$, Wieland Kiess $^{2,3}$ and Anja Hilbert ${ }^{1}$
}

\begin{abstract}
Background: While depressive symptoms and stress during pregnancy are known to affect gestational age and weight at birth, evidence on their impact on child anthropometric development in the long term remains limited, showing inconsistent effects. Importantly, previous research indicated a substantially stronger impact of categorically rather than dimensionally assessed mental health problems on birth outcomes and child development.

Methods: The Patient Health Questionnaire was used to assess depressive symptoms and stress during the 2nd trimester of pregnancy dimensionally and categorically, with scores $\geq 10$ indicating clinical significance. Gestational age at birth and BMI-SDS from birth up to 2 years of age were examined as dependent variables. Structural equation modeling was used to examine the prediction of birth outcomes and child anthropometry by mental health problems while controlling for multiple maternal and child characteristics in 322 mother-child dyads.

Results: Dimensionally assessed mental health problems did not significantly predict birth outcomes. While categorical depressive symptoms significantly predicted a higher child BMI-SDS, categorical stress significantly predicted a lower gestational age at birth. Neither categorical nor dimensional mental health problems significantly predicted child BMI-SDS at 6, 12, and 24 months postpartum.

Conclusions: Depressive symptoms and stress during pregnancy seem to differentially affect birth outcomes, and only if clinically relevant. The results implicate the importance to timely treat pregnant women that are greatly affected by mental health problems to potentially reduce adverse birth outcomes.
\end{abstract}

Keywords: Depression, Stress, Body mass index, Gestational age, Pregnancy, Children

\footnotetext{
*Correspondence: eichler_janina@web.de

${ }^{1}$ Integrated Research and Treatment Center AdiposityDiseases, Behavioral Medicine Research Unit, Department of Psychosomatic Medicine

and Psychotherapy, Leipzig University Medical Center, Semmelweisstrasse

10, 04103 Leipzig, Germany

Full list of author information is available at the end of the article
}

(c) The Author(s) 2021. Open Access This article is licensed under a Creative Commons Attribution 4.0 International License, which permits use, sharing, adaptation, distribution and reproduction in any medium or format, as long as you give appropriate credit to the original author(s) and the source, provide a link to the Creative Commons licence, and indicate if changes were made. The images or other third party material in this article are included in the article's Creative Commons licence, unless indicated otherwise in a credit line to the material. If material is not included in the article's Creative Commons licence and your intended use is not permitted by statutory regulation or exceeds the permitted use, you will need to obtain permission directly from the copyright holder. To view a copy of this licence, visit http://creativecommons.org/licenses/by/4.0/. The Creative Commons Public Domain Dedication waiver (http://creativeco mmons.org/publicdomain/zero/1.0/) applies to the data made available in this article, unless otherwise stated in a credit line to the data. 


\section{Background}

The prevalence of overweight and obesity in childhood is at a high level, with 38.2 million children up to 5 years of age having overweight or obesity worldwide [1]. Specifically, in Germany 15.4 and $5.9 \%$ of children and adolescents having overweight (age- and sex-specific percentile of the body mass index $[\mathrm{BMI}]>90$ th) or obesity (BMI percentile $>97$ th [2]). Crucially, longitudinal evidence showed that weight status is relatively stable from birth on [3]. For example, children who were large for gestational age at birth continuously had a higher BMI up to adolescence [3]. Particularly, lower birthweight and weight development during the first months of life were prospectively found to be key risk factors of central adiposity and weight-related comorbidities later in life [4]. Strikingly, recent evidence by Roy et al. showed that during the first 2 years of life a child's BMI was a better predictor for early childhood obesity than the anthropometric standard measure weight-forlength used in most previous studies [5]. Therefore, to reduce the current epidemic in overweight and obesity in children, it is important to examine early risk factors of adverse weight development from birth onwards.

"Fetal programming" describes the influence of gestational risk factors on child development and longterm health [6]. In the context of fetal programming of weight development, adverse intrauterine conditions were predictive for inadequately low or high birthweight and subsequent weight problems in children [7]. Besides maternal (e.g., age, socio-economic status, BMI, gestational weight gain, and pregnancy intention [8-10]) and behavioral risk factors (e.g., smoking and malnutrition $[11,12])$ mental health problems (e.g., depressive symptoms and stress [13-16]) were key conditions underlying fetal programming.

Concerning mental health problems during pregnancy, depressive symptoms showed high prevalence rates ranging between $9.2 \%$ for high and $19.2 \%$ for low and middle income countries [17]. Furthermore, up to 95\% of pregnant women reported at least one psychosocial stressor (e.g., financial problems or health concerns [18]). Maternal depressive symptoms and stress during pregnancy were negatively associated with gestational age at birth, birthweight, and birth length [14, $15,19-22]$ with 1 st or 2 nd trimester mental health problems showing strongest effects on birth outcomes [21]. Specifically, Accortt et al. systematically reviewed $N=83$ studies and found that 12 of 50 studies detected that higher levels of depressive symptoms predict lower gestational age at birth; 14 of 33 studies showed that higher levels of depressive symptoms predict lower birthweight; and 57 studies observed non-significant associations [15]. Similarly, meta-analytical evidence demonstrated stronger effects of depressive symptoms during pregnancy on birthweight than on gestational age at birth [14]. These effects were especially observed for depressive symptoms exceeding cut-offs that indicate clinical significance [20, 23]. Concerning stress during pregnancy, only small but significant effects were found for stress prospectively predicting gestational age at birth and birthweight [19]. Notably, while studies on major life events, community-wide catastrophes, or chronic stressors during pregnancy consistently found a negative association with gestational age at birth and birthweight, studies on daily stressors and perceived stress during pregnancy yielded heterogeneous, partially lacking effects $[16,22,23]$.

Besides programming of birth outcomes, mental health problems during pregnancy were found to influence child anthropometry in the long term [24]. However, there are only few prospective studies that examined the relation between depressive symptoms and stress during pregnancy and infant overweight and obesity, with mixed findings in samples of $n=181$ to 12,931 mother-child dyads [25-33]. Specifically, three studies found depressive symptoms during pregnancy to positively predict child BMI up to 6 months as well as leg length, and central adiposity at 3 years of age [26-28]; six studies indicated depressive symptoms to negatively predict child body length at 3 months, weight (-for-age) and child BMI up to 3 years of age, and child height at age 4 [26-30,32]; and three studies found no significant effects of depressive symptoms on child weight(-for-age) during the first year of life $[25,31,33]$. Evidence on the influence of stress during pregnancy on long-term child anthropometry is even weaker and focused solely on specific rather than chronic types of stress or stress of everyday life [28]. Maternal-reported family stress during the 2nd trimester significantly positively predicted BMI in $n=5328$ children aged between 3 months and 4 years after controlling for a large amount of confounders [28]. Maternal experience of racial discrimination or bereavement during pregnancy significantly negatively predicted child BMI at 3 years of age $(n=539$ [34]) or from 10years of age onwards ( $n=65,212$ [13]), respectively.

Given the small or inconsistent effects of fetal programming through mental health problems - especially stress - during pregnancy on anthropometric outcomes of the child, more evidence is needed to understand how depressive symptoms and stress differentially affect gestational age at birth and child anthropometry from birth onwards. Because previous studies mostly neglected birth length, but only considered birthweight as primary outcome, nothing is known about the adequacy of anthropometrics, which are more precisely reflected in the BMI at birth. Therefore, the aim of this study was to 
examine the influence of depressive symptoms and stress (i.e., personal impairment due to stressful events of everyday life) during pregnancy on gestational age at birth and standardized child BMI from birth up to 2 years of age in a population-based prospective cohort study of German mother-child dyads while controlling for various maternal and child characteristics. Consistent with previous research showing stronger effects using categorical rather than dimensional measures of mental health problems [14], we hypothesized that depressive symptoms and stress exceeding categorical cut-offs that indicate clinical significance would be inversely related to birth outcomes, while dimensionally assessed mental health problems would have no significant effect. Based on inconsistent effects of depressive symptoms and stress on standardized child BMI from birth onwards, we did not expect significant predictions of child anthropometry at 6,12 , and 24 months postpartum by mental health problems.

\section{Method}

\section{Participants and procedures}

Data from the BIRTH cohort of the "Leipzig Research Center for Civilization Diseases (LIFE) Child Study" were used in the current study, collected between 2011 and 2017. This prospective population-based cohort study examined pregnant women and their children from fetal life until adulthood. All pregnant women in the area of Leipzig (Germany) had the possibility to participate in the LIFE Child Study; no exclusion criteria were given. Women were recruited through advertisement at medical institutions and via media. Interested pregnant women obtained detailed information about the study, data use, potential risks of participation, their right to withdraw from the study at any time without explanations or negative consequences, and provided informed written consent prior to participation. At the time of recruitment, monetary incentives (at maximum 20 Euro per child) and small presents for the child were given to compensate for participation. Well-trained research assistants conducted assessments at visits during the 2nd and 3rd pregnancy trimester, and at child birth until 20 years of age (for detailed information, see [35, 36]). The Ethics committee of the University of Leipzig, Germany (reg. no. 264-1019042010) approved the study.

Because previous evidence suggests 1st or 2nd rather than 3rd trimester mental health problems to have a stronger impact on birth outcomes [21], 2nd trimester assessments were used in the current study. For the present study, the following inclusion criteria had to be met: (1) singleton pregnancy; valid data on (2) depressive symptoms or stress during the 2nd trimester; (3) child anthropometry and gestational age at birth; and (4) physical diseases during pregnancy. For the present analysis, (5) women were excluded when they self-reported diseases during pregnancy with potential influence on child anthropometry (i.e., vaginal bleeding during; hydramnios; oligohydramnios; placenta previa; placental insufficiency; anemia; urinary tract infection; gestational diabetes mellitus; hypo-; and hypertension). The eligible sample consisted of 463 mother-child dyads. A total of 139 mother-child dyads had to be excluded from the analyses due to not fulfilling inclusion criteria (1) to (5) as stated above: (1) $n=15$, (2) $n=89$, (3) $n=3$, (4) $n=6$, and (5) $n=26$, resulting in a final sample of $N=324$ motherchild dyads.

\section{Measures}

\section{Maternal characteristics}

Age, marital status, and pregnancy intention $(0=$ intended or $1=$ unintended $)$ were assessed by selfreport questionnaires at the 2 nd trimester visit. The Winkler Index based on income, education, and occupation was used to classify the socio-economic status (SES) of the family with a range between 3 and 21 $(3 \leq$ low $\leq 8 ; 9 \leq$ middle $\leq 14 ; 15 \leq$ high $\leq 21$ [37]). Pregravid height and weight were obtained through selfreport questionnaires during the 2nd trimester visit. Gestational weight gain $(\mathrm{kg})$ was computed by subtracting the pregravid weight from the objectively measured weight during the 2nd trimester visit via the calibrated scale "Seca 701" (Seca Gmbh \& Co. KG, Germany).

Maternal depressive symptoms and stress were assessed by corresponding modules of the German version of the Patient Health Questionnaire (PHQ-D [38, 39]). The self-report PHQ was developed to screen for stress-related symptoms and mental disorders according to DSM-IV [40]. The 9-item depression module PHQ-9 was used to assess depressive symptoms during the last 2 weeks $(0=$ not at all to $3=$ nearly every day [41]). In a previous study of $N=745$ pregnant women, the PHQ-9 showed high specificity (85\%) and sensitivity (84\%) for a depression diagnosis [42]. The 10-item stress module refers to personal impairment due to stressful events (e.g., financial problems, health concerns, or stress at work) during the last 4 weeks $(0=n o t$ impaired to $2=$ strongly impaired). Separate total scores were calculated for the depression and stress module by summing the items of each scale [38]. Scores of $\geq 10$ indicate depressive symptoms or stress of clinical significance $[39,41]$. To distinguish between pregnant women with and without symptoms of a major depressive disorder [41], and with and without moderate to high psychosocial stress scores we used these cut-offs in this study [39]. 


\section{Child characteristics}

Child sex $(0=$ female, $1=$ male $)$ and gestational age in weeks were determined at birth by physicians. Child weight and height were measured by physicians at various health check-ups including at $2-4 \mathrm{~h}$ (birth); 6-7 months (6 m); 10-12 months (12 m); and 21-24 months $(24 \mathrm{~m})$ after birth. As the child's BMI was found to be a better predictor for early childhood obesity than weight-for-length measure, BMI was calculated $\left(\mathrm{kg} / \mathrm{m}^{2}[5]\right)$ and transformed into sex- and agespecific BMI-standard deviation scores (BMI-SDS [43]).

\section{Statistical analysis}

Data preparation included Shapiro-Wilks tests of normal distribution for all variables and checks for plausibility. Outlier analyses were conducted for gestational weight gain ( $n=1$ outlier), depressive symptoms ( $n=6$ outliers), and stress ( $n=6$ outliers), deleting normally or non-normally distributed data which were 3 standard deviations under or above the mean of each variable. Because of outliers in both mental health problems, $n=2$ pregnant women had to be excluded from the analyses, resulting in a final sample of $N=322$. SPSS for Windows (Version 22.0; SPSS, Inc., Chicago, IL) was used for descriptive statistical analyses.

Path analysis using structural equation modeling (SEM) was conducted to examine the influence of mental health problems on gestational age at birth and BMI-SDS at birth, $6 \mathrm{~m}, 12 \mathrm{~m}$, and $24 \mathrm{~m}$ using Amos (Version 20.0; IBM SPSS, Inc., Chicago, IL, USA). Path analysis was

Table 1 Prevalence rates, means, and standard deviations of study variables

\begin{tabular}{|c|c|c|c|}
\hline Variable & $n$ & $M \pm S D$ & $n / \%$ \\
\hline \multicolumn{4}{|l|}{ Mental health problems } \\
\hline Depressive symptoms (PHQ-9) & 318 & & \\
\hline Dimensional & & $4.89 \pm 2.96$ & \\
\hline Categorical (cut-off $\geq 10$ ) & & & $27 / 8.5 \%$ \\
\hline Stress (PHQ-D) & 318 & & \\
\hline Dimensional & & $3.88 \pm 2.93$ & \\
\hline Categorical (cut-off $\geq 10$ ) & & & $18 / 5.7 \%$ \\
\hline \multicolumn{4}{|l|}{ Maternal characteristics } \\
\hline Pregravid BMI (kg/m²) & 318 & $23.42 \pm 4.41$ & \\
\hline Gestational weight gain until 2nd trimester (kg) & 282 & $6.88 \pm 3.64$ & \\
\hline Maternal age (years) & 322 & $30.33 \pm 4.17$ & \\
\hline Winkler Index of the family & 234 & $14.01 \pm 3.91$ & \\
\hline Low socio-economic status (3-8) & & & $18 / 7.7 \%$ \\
\hline Middle socio-economic status (9-14) & & & $101 / 43.2 \%$ \\
\hline High socio-economic status (15-21) & & & $115 / 49.1 \%$ \\
\hline Pregnancy intention (planned, yes) & 292 & & $243 / 83.2 \%$ \\
\hline Parity (primigravid) & 322 & & $304 / 94.4 \%$ \\
\hline \multicolumn{4}{|l|}{ Child characteristics } \\
\hline Birth (health check-up at 2-4h) & 322 & & \\
\hline $\mathrm{BMI}\left(\mathrm{kg} / \mathrm{m}^{2}\right)$ & & $13.67 \pm 1.30$ & \\
\hline BMI-SDS & & $0.86 \pm 1.07$ & \\
\hline $6 \mathrm{~m}$ (health check-up at 6-7 months) & 271 & & \\
\hline BMI $\left(\mathrm{kg} / \mathrm{m}^{2}\right)$ & & $16.71 \pm 1.49$ & \\
\hline BMI-SDS & & $0.12 \pm 1.08$ & \\
\hline $12 \mathrm{~m}$ (health check-up at 10-12 months) & 256 & & \\
\hline $\operatorname{BMI}\left(\mathrm{kg} / \mathrm{m}^{2}\right)$ & & $16.71 \pm 1.46$ & \\
\hline BMI-SDS & & $-0.03 \pm 1.43$ & \\
\hline $24 \mathrm{~m}$ (health check-up at 21-24 months) & 218 & & \\
\hline BMI $\left(\mathrm{kg} / \mathrm{m}^{2}\right)$ & & $16.35 \pm 1.35$ & \\
\hline BMI-SDS & & $0.15 \pm 0.97$ & \\
\hline Gestational age at birth (weeks) & 322 & $39.30 \pm 1.48$ & \\
\hline
\end{tabular}

Note. $n=$ number of pregnant women included in the model; PHQ-9 Patient Health Questionnaire-Depression, $P H Q-D$ Patient Health Questionnaire-German version, $B M I$ body mass index, SDS standard deviation score 


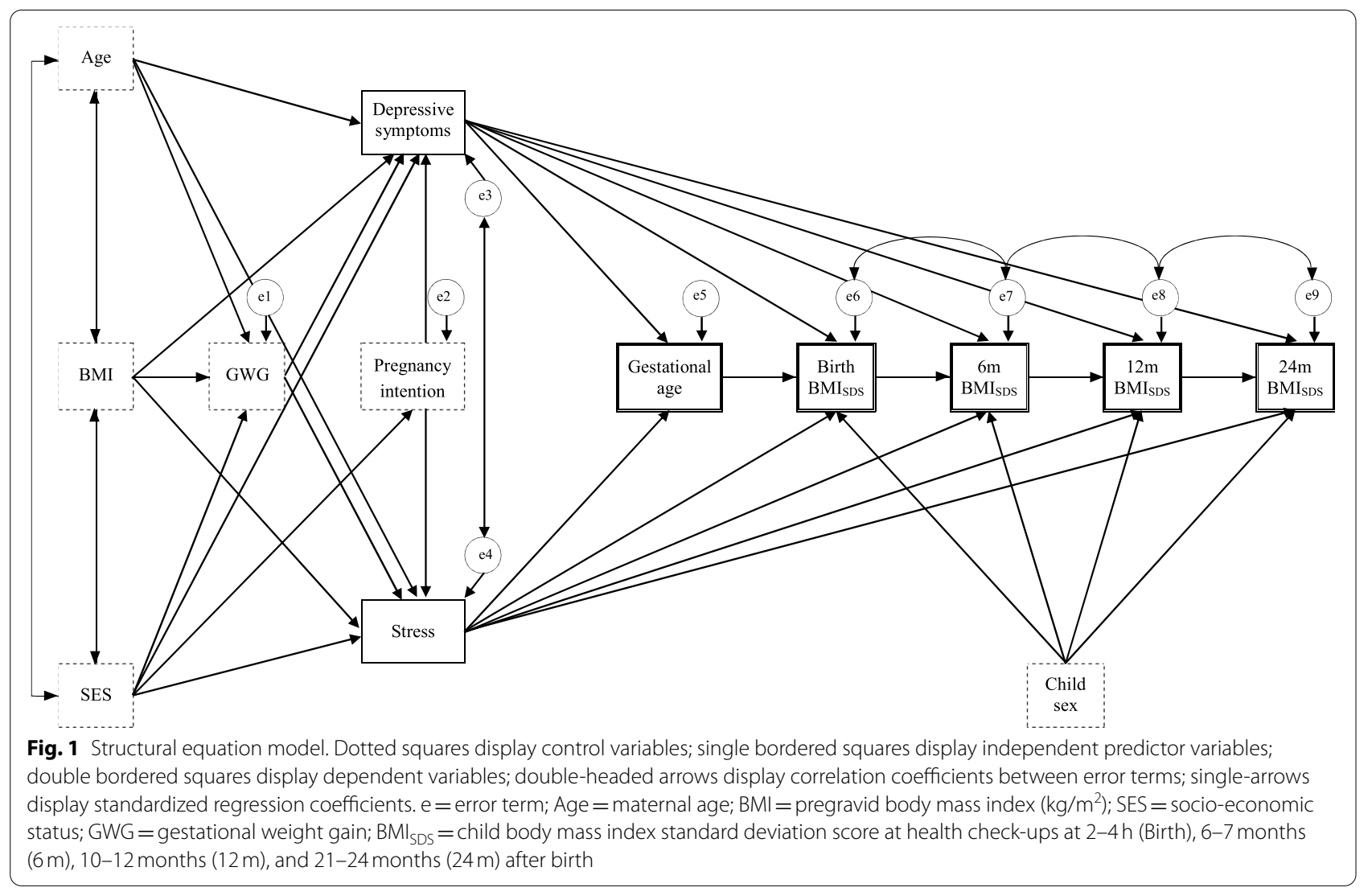

run twice, once using dimensional (Model 1) and once using categorical mental health problems $(0=$ women without depressive symptoms or stress of clinical significance, $1=$ women with depressive symptoms or stress of clinical significance; Model 2). According to existing evidence, maternal age, pregravid BMI, gestational weight gain, SES of the family, pregnancy intention, and child sex were entered as control variables in all analyses [9, 10, 44-46]. For handling missing data (for $n$ of each variable, see Table 1), full information maximum likelihood method was used. Figure 1 displays the model of the path analyses. Relative strength of the examined relations was indicated by standardized $\beta$ s. Model fit indices with recommended cut-offs were used to determine goodness of fit: $\chi^{2}(p>.05)$, root-mean-square error of approximation (RMSEA $\leq .05)$, comparative fit index $(\mathrm{CFI} \geq .95)$, Tucker-Lewis index (TLI $\geq .95$ [47]) and minimum discrepancy divided by its degrees of freedom (CMIN/ $\mathrm{df}<2$ ). Statistical significance was set to a two-tailed $p<.05$.

\section{Results}

\section{Sample characteristics}

Table 1 displays prevalence rates, means, and standard deviations of the measured study variables. Pregnant women during the 2nd trimester were 20 to 43 years old $(M=30.3, S D=4.2)$ and reported a mean pregravid BMI $(n=318)$ of $23.4 \pm 4.4 \mathrm{~kg} / \mathrm{m}^{2}$ ranging from 17.2 to $48.4 \mathrm{~kg} /$ $\mathrm{m}^{2}$. Mean gestational weight gain until the 2 nd trimester was $6.9 \pm 3.6 \mathrm{~kg}$ ranging from -3.8 to $18.1 \mathrm{~kg}(n=282)$. Socio-demographically, a major proportion of the pregnant women reported to be partnered $(95.7 \%, n=243$ of $254)$, a middle (43.2\%, $n=101$ of 234 ) to high SES (49.1\%, $n=115$ of 234), had planned to become pregnant (83.2\%, $n=243$ of 292), and were primigravid ( $94.4 \%, n=304$ of $322)$. Concerning mental health problems, $8.5 \%(n=27$ of 318$)$ and $5.7 \%(n=18$ of 318$)$ of pregnant women exceeded the cut-offs for depressive symptoms and stress of clinical significance, respectively. Only a minor proportion of the sample exceeded the cut-offs for both depressive symptoms and stress $(1.9 \%, n=6$ of 314$)$. A minority of pregnant women gave birth preterm $(4.3 \%$, $n=14$ of 322 ), with earliest birth at gestational week 31 .

\section{Predictors of gestational age at birth and child anthropometry}

Model fit indices for the path analyses for Model 1, $\chi^{2}(39)=51.770, \quad p=.083 ; \quad$ RMSEA $=.032 ; \quad C F I=.966$; $\mathrm{TLI}=.920 ; \quad \mathrm{CMHIN} / \mathrm{df}=1.327, \quad$ and Model 2, 


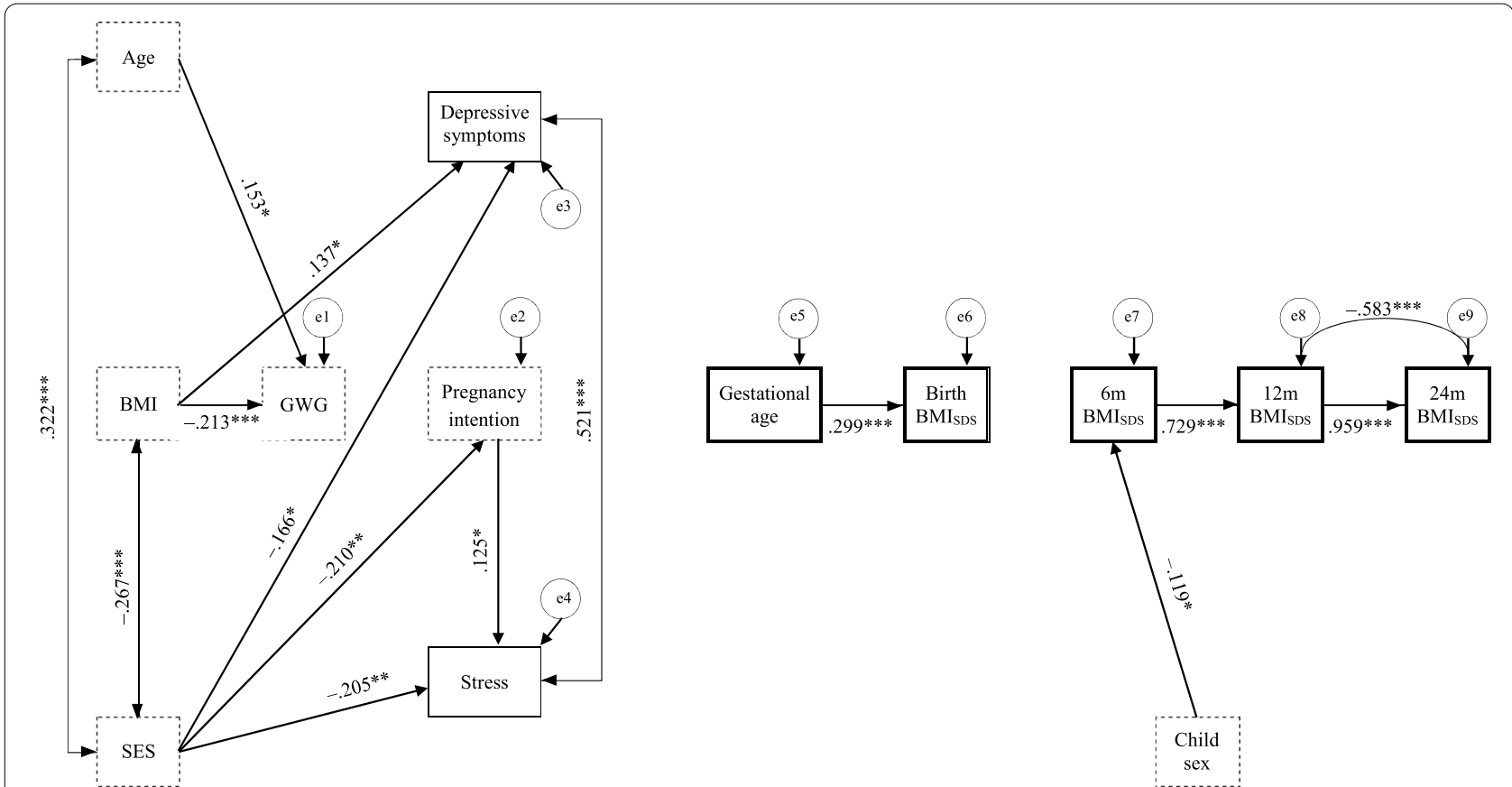

Fig. 2 Structural equation Model 1 using dimensional mental health problems to predict gestational age at birth and infant anthropometry. Dotted squares display control variables; single bordered squares display independent predictor variables; double bordered squares display dependent variables; double-headed arrows display correlation coefficients between error terms; single-headed arrows display standardized regression coefficients. $\mathrm{e}=$ error term; Age = maternal age; $\mathrm{BMI}=$ pregravid body mass index $\left(\mathrm{kg} / \mathrm{m}^{2}\right)$; SES = socio-economic status; GWG = gestational weight gain; $\mathrm{BMI}_{\mathrm{SDS}}=$ child body mass index standard deviation score at health check-ups at 2-4h (Birth), 6-7 months (6 m), 10-12 months (12 m), and $21-24$ months $(24 \mathrm{~m})$ after birth. ${ }^{* * *} p<.001,{ }^{* *} p<.01,{ }^{*} p<.05$

$\chi^{2}(39)=52.755, \quad p=.070 ; \quad$ RMSEA $=.033 ; \quad$ CFI $=.954 ;$ $\mathrm{TLI}=.893 ; \mathrm{CMHIN} / \mathrm{df}=1.353$ were within the recommended cut-offs except the slightly lower TLIs, overall proving goodness of fit.

Figure 2 displays all significant paths of SEM for Model 1. Neither dimensional depressive symptoms nor stress during the 2nd trimester significantly predicted gestational age at birth or child anthropometry until 2 years of age (all $p s \geq .05$ ).

Fig. 3 shows all significant paths of SEM for Model 2. Categorically, depressive symptoms of clinical significance significantly positively predicted BMI-SDS at birth $(p=.044)$ and stress of clinical significance significantly negatively predicted gestational age at birth $(p=.047)$.

\section{Discussion}

To our knowledge, this is the first study that examined the influence of dimensional and categorical maternal depressive symptoms and stress during the 2nd pregnancy trimester on gestational age at birth and standardized child BMI from birth up to 2 years of age while controlling for multiple maternal and child characteristics in a population-based sample of German motherchild dyads. While dimensionally assessed depressive symptoms and stress were not associated with birth outcomes or child anthropometry at any age, depressive symptoms and stress of clinical significance significantly predicted a higher child BMI at birth and lower gestational age at birth, respectively.

In line with two previous systematic reviews showing larger effect sizes of categorically rather than dimensionally measured depressive symptoms or stress on gestational age and weight at birth $[15,22]$, mental health problems of clinical significance significantly predicted birth outcomes. The fact that depressive symptoms of clinical significance significantly predicted higher child BMI at birth, which is known to predict a continuously higher BMI up to adolescence [3], indicated that clinically relevant depressive symptoms during pregnancy may indirectly heighten the risk for overweight and obesity in children. Similarly, Ecklund-Flores et al. found a significant positive effect of depressive symptoms during the 3rd trimester on birthweight, while controlling for gestational age at birth [48]. Notably, most previous research demonstrating an inverse relation between depressive symptoms and birthweight did not control for gestational age [48], which may bias the results. Additionally, the majority of previous studies used birthweight rather than BMI at birth as their main outcome, with neglecting birth length. The fact that depressive symptoms of clinical 


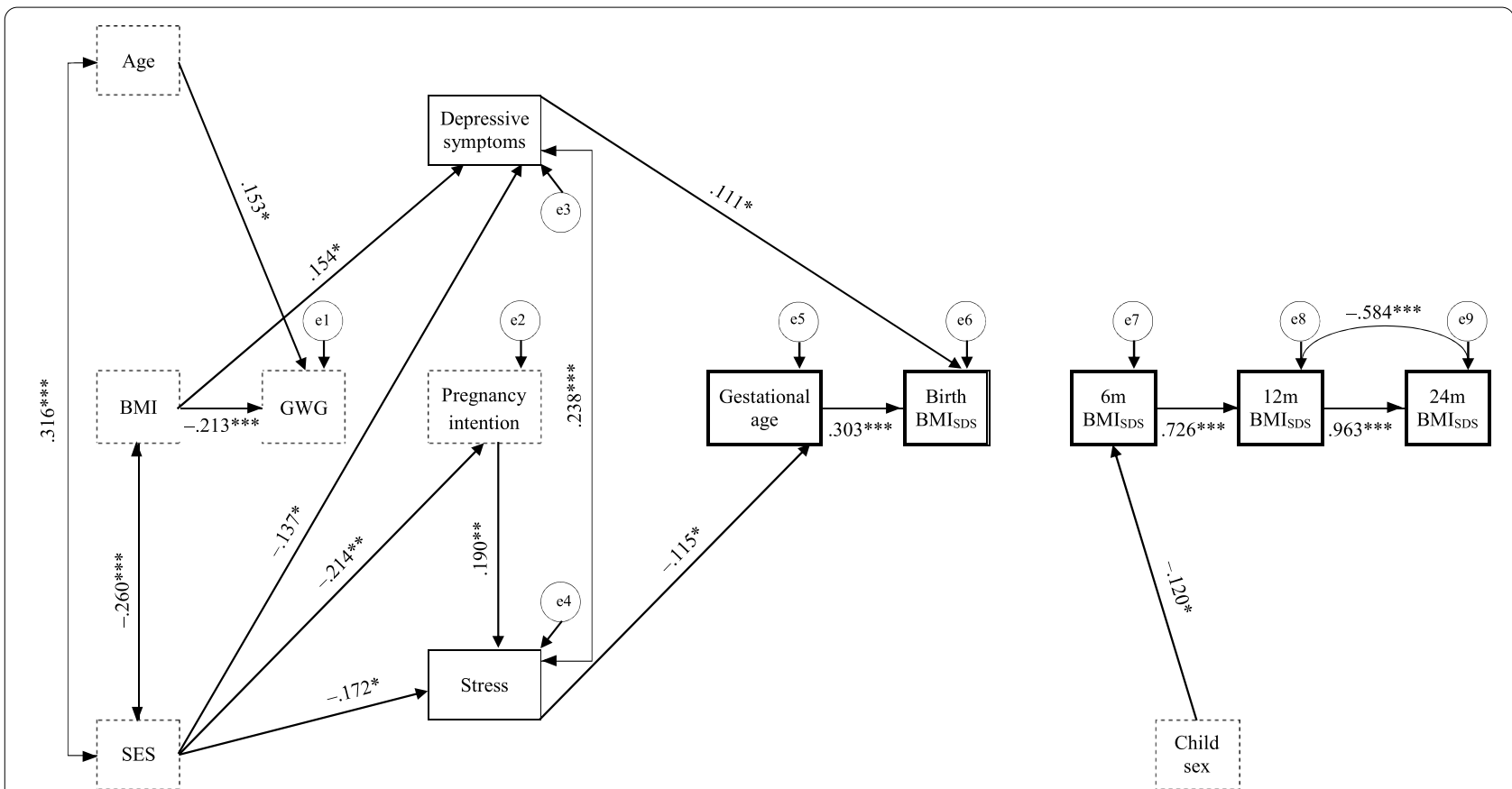

Fig. 3 Structural equation Model 2 using categorical mental health problems to predict gestational age at birth and infant anthropometry. Dashed squares display control variables; single bordered squares display independent predictor variables; double bordered squares display dependent variables; double-headed arrows display correlation coefficients between error terms; single-headed arrows display standardized regression coefficients. $\mathrm{e}=$ error term; Age = maternal age; $\mathrm{BMI}=$ pregravid body mass index $\left(\mathrm{kg} / \mathrm{m}^{2}\right) ; \mathrm{SES}=$ socio-economic status; $\mathrm{GWG}=$ gestational weight gain; $\mathrm{BMI}_{\mathrm{SDS}}=$ child body mass index standard deviation score at health check-ups at 2-4h (Birth), 6-7 months (6 m), 10-12 months (12 m), and $21-24$ months $(24 \mathrm{~m})$ after birth. ${ }^{* * *} p<.001,{ }^{* *} p<.01,{ }^{*} p<.05$

significance predicted child BMI but not gestational age at birth is in line with previous evidence suggesting that depressive symptoms during pregnancy influence intrauterine growth, but do not cause pregnancy complications resulting in preterm or delayed birth [20, 23]. Stress of clinical significance negatively influenced the length of gestation, which is known to cause medical and social disabilities up to adulthood [49]. Though the effect size was small it was comparable to effect sizes found in previous research [19].

Dimensionally assessed mental health problems did not significantly predict birth outcomes. These findings were in line with expectations and previous research showing that $75 \%$ of 50 studies on predicting gestational age at birth and $47 \%$ of 33 studies on predicting child anthropometry at birth by depressive symptoms revealed non-significant results [15]. The lack of effect in predicting birth outcomes by dimensionally assessed stress is consistent with previous research focusing on stressors of everyday life during pregnancy suggesting that, stress due to major life events, community-wide catastrophes, and chronic stressors may be more relevant for child health outcomes [22]. In addition, as stress covers a broad construct with previous research merging symptoms of anxiety and distress with stress [19], different operationalization of stress may play a role when interpreting the findings.

The result that neither dimensionally nor categorically assessed mental health problems significantly predicted child BMI from 6 to 24 months postpartum is in line with expectations. It strengthened previous evidence showing no significant influence of depressive symptoms during pregnancy on child BMI in $n=168$ to 12,391 children up to 3 years of age [25, 31, 33]. Studies reporting a significant positive or negative influence of depressive symptoms on child anthropometry found mainly small effects and revealed that chronic rather than episodic depressive symptoms during pregnancy might have a stronger impact on child anthropometry $[26,27,29,30,32]$. Concerning stress, our study adds unique evidence on the influence of chronic stressors of everyday life on child BMI to few previous studies on more specific types of stress (i.e., family stress, racial discrimination, and bereavement [13, 28, 34]). Taken together this suggests that major life events and chronic stressors may be more relevant in influencing child anthropometry than stressors of everyday life. According to our results and the inconsistency of previous results $[28,29,33]$, it is likely that child characteristics (i.e., child sex and anthropometry) have a stronger 
impact on child BMI development than maternal mental health problems during pregnancy. Additionally, environmental factors related to mental health problems (e.g., family environment) might play a greater role in child BMI development than maternal mental health problems alone [28].

\section{Strengths, limitations, and future directions}

A key strength of the present study is the prospectively assessed population-based sample of pregnant women excluding those with physical diseases during pregnancy with potential influence on child anthropometry. Mental health problems were assessed by an internationally established questionnaire showing good psychometric properties [38, 39, 42]. Confounding was minimized by examining depressive symptoms and stress simultaneously in the same model. Additional strengths include the objective multiple measurements of weight and height from birth up to 2 years of age. We controlled for many maternal and child characteristics known to affect gestational age at birth and child BMI from birth onwards. However, as a first limitation, we did not control for antidepressant use which might have biased the results because of its adverse effects on birth outcomes [50]. Second, only German women during the 2nd trimester of pregnancy were included reducing generalizability of the results to other nationalities or pregnancy trimesters, respectively. Third, the sample was selective in terms of a relatively high socio-economic status, which is a typical observation in population-based studies of pregnant women [51] and may be related to low levels of overweight and obesity and a low rate of medical complications in the present sample. In addition, the sample may be selective in terms of high pregnancy intention; bi-directional effects between pregnancy intention and health behavior may have a protective influence on women's mental health problems. Thus, our results might not be generalizable to populations with a higher risk of experiencing mental health problems or comorbidities during pregnancy. Fourth, because self-report measurement of mental health problems may not accurately reflect health status, objective measurement (e.g., standardized interviews, physiological, and biochemical markers) would have been preferable, but is difficult to implement in a large population-based study. Finally, there was missing data on child BMI at 6,12 , and 24 months, but was corrected based on the full information maximum likelihood method.

The present study is a foundation for future research to further analyze the mechanisms contributing to adverse birth outcomes and child anthropometry from birth onwards. Because the effects of depressive symptoms and stress of clinical significance on birth outcomes and child BMI development up to 2 years of age were found to be small or non-significant, respectively, we recommend future research to assess mental health problems more than once during pregnancy (e.g., episodic versus chronic [28]) and in the postnatal period [27]; examine specific psychosocial symptoms more comprehensively (e.g., pregnancy-related concerns, family stress, and anxiety [22]); use objective assessment methods (e.g., blood examination); and consider other potentially confounding variables during pregnancy (e.g., maternal and behavioral risk factors $[8,11]$ ) and in the perinatal period (e.g., non-breastfeeding, early introduction of solid foods [52]). Nevertheless, the results underline the importance of screening for mental health problems during pregnancy to immediately offer treatment (e.g., cognitive-behavioral therapy, group therapy, educational programs) to pregnant women affected by depressive symptoms and stress of clinical significance in order to potentially reduce the risk for adverse birth outcomes and postpartum depression [15].

\section{Conclusion}

Pregnant women with depressive symptoms or stress of clinical significance had children with a higher BMI or gave birth at an earlier gestational age, respectively, than pregnant women without or only few depressive symptoms and stress during pregnancy. However, depressive symptoms and stress during pregnancy in otherwise healthy mothers did not lead to adverse child weight development from 6 months up to 2 years of age.

\section{Abbreviations}

BMI: Body mass index; BMI-SDS: Body mass index standard deviation score LIFE: Leipzig Research Center for Civilization Diseases; PHQ: Patient Health Questionnaire; pRR: Pooled relative risk; SEM: Structural equation modeling; SES: Socio-economic status; $6 \mathrm{~m}$ : Health check-up at 6-7 months after birth; $12 \mathrm{~m}$ : Health check-up at 10-12 months after birth; $24 \mathrm{~m}$ : Health check-up at 21-24 months after birth.

\section{Acknowledgments}

We would like to thank the study team, all participating parents, and their children. Thanks to Katharina Eichler for proofreading the manuscript and Jana Cämmerer for participation in conceiving the protocol.

\section{Authors' contributions}

$\mathrm{JE}$, RS, and AHil conceived the protocol. WK, AHie, and TP contributed to data collection. JE analyzed the data. All authors were involved in writing and approving the submitted and published versions.

\section{Funding}

The "Leipzig Research Centre for Civilization Diseases" (LIFE) and the Integrated Research and Treatment Center AdiposityDiseases of Leipzig University supported this research. LIFE was funded by means of the European Union, European Regional Development Fund (ERDF), and the Free State of Saxony. AHil and RS were funded by the German Federal Ministry of Education and Research (grant 01EO1501). Open Access funding enabled and organized by Projekt DEAL. 


\section{Availability of data and materials}

The datasets used and/or analyzed during the current study are available from the corresponding author on reasonable request.

\section{Declarations}

\section{Ethics approval and consent to participate}

The study was approved by the Ethics committee of the University of Leipzig Germany (reg. no. 264-10-19042010). The authors assert that all procedures contributing to this work comply with the ethical standards of the relevant national and institutional committees on human experimentation and with the Helsinki Declaration of 1975, as revised in 2008. Informed written consent was obtained from all pregnant women.

\section{Consent for publication}

Not applicable.

\section{Competing interests}

The authors declare that they have no competing interests.

\section{Author details}

${ }^{1}$ Integrated Research and Treatment Center AdiposityDiseases, Behavioral Medicine Research Unit, Department of Psychosomatic Medicine and Psychotherapy, Leipzig University Medical Center, Semmelweisstrasse 10, 04103 Leipzig, Germany. ${ }^{2}$ LIFE Child Leipzig Research Center for Civilization Diseases, Leipzig University, Philipp-Rosenthal-Strasse 27, 04103 Leipzig, Germany. ${ }^{3}$ Department of Women and Child Health, Hospital for Children and Adolescents and Centre for Paediatric Research (CPL), Leipzig University, Liebigstrasse 20a, 04103 Leipzig, Germany.

Received: 19 January 2021 Accepted: 29 August 2021

Published online: 18 September 2021

\section{References}

1. World Health Organization (WHO). Obesity and overweight. Available at: https://www.who.int/en/news-room/fact-sheets/detail/obesity-andoverweight (Accessed 28 July 2020).

2. Schienkiewitz A, Brettschneider AK, Damerow S, Rosario AS. Übergewicht und Adipositas im Kindes- und Jugendalter in Deutschland - Querschnittergebnisse aus KiGGS Welle 2 und trends. JoHM. 2018;3:16-23

3. Geserick M, Vogel M, Gausche R, LipekT, Spielau U, Keller E, et al. Acceleration of BMI in early childhood and risk of sustained obesity. N Engl J Med. 2018:379:1303-12.

4. Oken E, Gillman MW. Fetal origins of obesity. Obes Res. 2003;11:496-506.

5. Roy SM, Spivack JG, Faith MS, Chesi A, Mitchell JA, Kelly A, et al. Infant $\mathrm{BMI}$ or weight-for-length and obesity risk in early childhood. Pediatrics. 2016;137:e20153492.

6. Barker DJ. The fetal and infant origins of adult disease. BMJ. 1990;301:1111.

7. Calkins K, Devaskar SU. Fetal origins of adult disease. Curr Probl Pediatr Adolesc Health Care. 2011;41:158-76.

8. Preston JD, Reynolds LJ, Pearson KJ. Developmental origins of health span and life span: a mini-review. Gerontology. 2018;64:237-45.

9. Blumenshine P, Egerter S, Barclay CJ, Cubbin C, Braveman PA. Socioeconomic disparities in adverse birth outcomes: a systematic review. Am J Prev Med. 2010;39:263-72

10. Shah PS, Balkhair T, Ohlsson A, Beyene J, Scott F, Frick C. Intention to become pregnant and low birth weight and preterm birth: a systematic review. Matern Child Health J. 2011:15:205-16.

11. Wu G, Bazer FW, Cudd TA, Meininger CJ, Spencer TE. Maternal nutrition and fetal development. J Nutr. 2004:134:2169-72.

12. Pereira PPS, Da Mata, Figueiredo ACG, de Andrade KRC, Pereira MG. Maternal active smoking during pregnancy and low birth weight in the Americas: a systematic review and meta-analysis. Nicotine Tob Res. 2017:19:497-505
13. Li J, Olsen J, Vestergaard M, Obel C, Baker JL, Sorensen TIA. Prenatal stress exposure related to maternal bereavement and risk of childhood overweight. PLoS One. 2010:5:e11896.

14. Grote NK, Bridge JA, Gavin AR, Melville JL, lyengar S, Katon WJ. A metaanalysis of depression during pregnancy and the risk of preterm birth low birth weight, and intrauterine growth restriction. Arch Gen Psychiatry. 2010:67:1012-24.

15. Accortt EE, Cheadle ACD, Dunkel SC. Prenatal depression and adverse birth outcomes: an updated systematic review. Matern Child Health J. 2015;19:1306-37

16. Lima SAM, El Dib RP, Rodrigues MRK, Ferraz GAR, Molina AC, Neto CAP, et al. Is the risk of low birth weight or preterm labor greater when maternal stress is experienced during pregnancy? A systematic review and meta-analysis of cohort studies. PLoS One. 2018;13:e0200594.

17. Woody CA, Ferrari AJ, Siskind DJ, Whiteford HA, Harris MG. A systematic review and meta-regression of the prevalence and incidence of perinatal depression. J Affect Disord. 2017;219:86-92.

18. Eichler J, Schmidt R, Hiemisch A, Kiess W, Hilbert A. Gestational weight gain, physical activity, sleep problems, substance use, and food intake as proximal risk factors of stress and depressive symptoms during pregnancy. BMC Pregnancy Childbirth. 2019;19:175.

19. Bussières E-L, Tarabulsy GM, Pearson J, Tessier R, Forest J-C, Giguère Y. Maternal prenatal stress and infant birth weight and gestational age: a meta-analysis of prospective studies. Dev Rev. 2015;36:179-99.

20. Jarde A, Morais M, Kingston D, Giallo R, MacQueen GM, Giglia L, et al. Neonatal outcomes in women with untreated antenatal depression compared with women without depression: a systematic review and meta-analysis. JAMA Psychiatry. 2016;73:826-37.

21. Khashan AS, Everard C, McCowan LME, Dekker G, Moss-Morris R, Baker $\mathrm{PN}$, et al. Second-trimester maternal distress increases the risk of small for gestational age. Psychol Med. 2014:44:2799-810.

22. Dunkel SC. Psychological science on pregnancy: stress processes, biopsychosocial models, and emerging research issues. Annu Rev Psychol. 2011;62:531-58.

23. Dunkel Schetter C, Tanner L. Anxiety, depression and stress in pregnancy: implications for mothers, children, research, and practice. Curr Opin Psychiatry. 2012;25:141-8.

24. Entringer $\mathrm{S}$. Impact of stress and stress physiology during pregnancy on child metabolic function and obesity risk. Curr Opin Clin Nutr Metab Care. 2013;16:320-7.

25. Drewett $R$, Blair $P$, Emmett $P$, Emond $A$. Failure to thrive in the term and preterm infants of mothers depressed in the postnatal period: a population-based birth cohort study. J Child Psychol Psychiatry. 2004;45:359-66.

26. Ertel KA, Koenen KC, Rich-Edwards JW, Gillman MW. Maternal depressive symptoms not associated with reduced height in young children in a US prospective cohort study. PLoS One. 2010;5:e13656.

27. Ertel KA, Koenen KC, Rich-Edwards JW, Gillman MW. Antenatal and postpartum depressive symptoms are differentially associated with early childhood weight and adiposity. Paediatr Perinat Epidemiol. 2010;24:179-89.

28. Guxens $M$, Tiemeier $H$, Jansen PW, Raat H, Hofman A, Sunyer J, et al. Parental psychological distress during pregnancy and early growth in preschool children: the generation R study. Am J Epidemiol. 2013;177:538-47

29. Park H, Sundaram R, Gilman SE, Bell G, Louis GMB, Yeung EH. Timing of maternal depression and sex-specific child growth, the upstate KIDS study. Obesity. 2018;26:160-6.

30. Rahman A, lqbal Z, Bunn J, Lovel H, Harrington R. Impact of maternal depression on infant nutritional status and illness: a cohort study. Arch Gen Psychiatry. 2004:61:946-52.

31. Wisner KL, Bogen DL, Sit D, McShea M, Hughes C, Rizzo D, et al. Does fetal exposure to SSRIs or maternal depression impact infant growth? Am J Psychiatry. 2013;170:485-93.

32. Wojcicki JM, Holbrook K, Lustig RH, Epel E, Caughey AB, Muñoz RF, et al. Chronic maternal depression is associated with reduced weight gain in latino infants from birth to 2 years of age. PLoS One. 2011:6:e16737.

33. Phelan S, Hart C, Phipps M, Abrams B, Schaffner A, Adams A, et al. Maternal behaviors during pregnancy impact offspring obesity risk. Exp Diabetes Res. 2011;2011:985139. 
34. Dixon B, Rifas-Shiman SL, James-Todd T, Ertel K, Krieger N, Kleinman KP, et al. Maternal experiences of racial discrimination and child weight status in the first 3 years of life. J Dev Orig Health Dis. 2012;3:433-41.

35. Poulain T, Baber R, Vogel M, Pietzner D, Kirsten T, Jurkutat A, et al. The LIFE child study: a population-based perinatal and pediatric cohort in Germany. Eur J Epidemiol. 2017;32:145-58

36. Quante M, Hesse M, Dohnert M, Fuchs M, Hirsch C, Sergeyev E, et al. The LIFE child study: a LIFE course approach to disease and health. BMC Public Health. 2012:12:1021.

37. Winkler J, Stolzenberg H. Der Sozialschichtindex im Bundes-Gesundheitssurvey. Gesundheitswesen. 1999;61(2):178-83 Available at: https:// www.researchgate.net/publication/12590351_Social_class_index_in_ the_Federal_Health_Survey_in_German.

38. Gräfe K, Zipfel S, Herzog W, Löwe B. Screening psychischer Störungen mit dem "Gesundheitsfragebogen für Patienten (PHQ-D)". Diagnostica. 2004;50:171-81.

39. Spitzer RL, Kroenke K, Williams JBW, Patient Health Questionnaire Primary Care Study Group. Validation and utility of a self-report version of PRIMEMD: the PHQ primary care study. JAMA. 1999;282:1737.

40. American Psychiatric Association. Diagnostic and statistical manual of mental disorders. Washington, DC: American Psychiatric Association; 2000.

41. Kroenke K, Spitzer RL, Williams JB. The PHQ-9: validity of a brief depression severity measure. J Gen Intern Med. 2001;16:606-13.

42. Sidebottom AC, Harrison PA, Godecker A, Kim H. Validation of the patient health questionnaire (PHQ)-9 for prenatal depression screening. Arch Womens Ment Health. 2012:15:367-74.

43. Voigt M, Schneider KT, Jährig K. Analyse des Geburtengutes des Jahrgangs 1992 der Bundesrepublik Deutschland. Teil 1: Neue Perzentilwerte für die Körpermasse von Neugeborenen. Geburtshilfe Frauenheilkd. 1996:56:550-8.
44. Di Renzo GC, Rosati A, Sarti RD, Cruciani L, Cutuli AM. Does fetal sex affect pregnancy outcome? Gend Med. 2007;4:19-30.

45. Frederick IO, Williams MA, Sales AE, Martin DP, Killien M. Pre-pregnancy body mass index, gestational weight gain, and other maternal characteristics in relation to infant birth weight. Matern Child Health J. 2008;12:557-67.

46. Cleary-Goldman J, Malone FD, Vidaver J, Ball RH, Nyberg DA, Comstock $\mathrm{CH}$, et al. Impact of maternal age on obstetric outcome. Obstet Gynecol. 2005;105:983-90.

47. lacobucci D. Structural equations modeling: fit indices, sample size, and advanced topics. J Consum Psychol. 2010;20:90-8.

48. Ecklund-Flores L, Myers MM, Monk C, Perez A, Odendaal HJ, Fifer WP. Maternal depression during pregnancy is associated with increased birth weight in term infants. Dev Psychobiol. 2017:59:314-23.

49. Moster D, Lie RT, Markestad T. Long-term medical and social consequences of preterm birth. N Engl J Med. 2008;359:262-73.

50. Huang H, Coleman S, Bridge JA, Yonkers K, Katon W. A meta-analysis of the relationship between antidepressant use in pregnancy and the risk of preterm birth and low birth weight. Gen Hosp Psychiatry. 2014;36:13-8.

51. Jaddoe WWV, van Duijn CM, van der Heijden A, Mackenbach JP, Moll HA, Steegers EAP, et al. The generation R study: design and cohort update 2010. Eur J Epidemiol. 2010;25:823-41.

52. Weng SF, Redsell SA, Swift JA, Yang M, Glazebrook CP. Systematic review and meta-analyses of risk factors for childhood overweight identifiable during infancy. Arch Dis Child. 2012;97:1019-26.

\section{Publisher's Note}

Springer Nature remains neutral with regard to jurisdictional claims in published maps and institutional affiliations.
Ready to submit your research? Choose BMC and benefit from:

- fast, convenient online submission

- thorough peer review by experienced researchers in your field

- rapid publication on acceptance

- support for research data, including large and complex data types

- gold Open Access which fosters wider collaboration and increased citations

- maximum visibility for your research: over $100 \mathrm{M}$ website views per year

At BMC, research is always in progress.

Learn more biomedcentral.com/submissions 